ZANÃO JÚNIOR, L.A.; LANA, R.M.Q.; SÁ, K.A. Formas de parcelamento e fontes de adubação nitrogenada para produção de couve-da-Malásia. Horticultura Brasileira, Brasília, v.23, n.4, p.965-969, out-dez 2005.

\title{
Formas de parcelamento e fontes de adubação nitrogenada para produ- ção de couve-da-Malásia
}

\author{
Luiz Antônio Zanão Júnior ${ }^{1}$; Regina Maria Q. Lana²; Kátia Aparecida de Sá2 \\ ${ }^{1}$ UFV, Depto. Solos, 36570-000 Viçosa-MG; 2UFU - ICIAG; E-mail: luizantoniozanao@yahoo.com
}

\begin{abstract}
RESUMO
A couve-da-Malásia, Brassica chinensis L. var. parachinensis (Bailey) é muito cultivada na China, Austrália e outros países do sudeste asiático e foi introduzida no Brasil em 1992. Existem poucas informações referentes à nutrição mineral desta Brássica nas condições brasileiras. O objetivo do presente trabalho foi avaliar o efeito de fontes e parcelamento do nitrogênio na produtividade e teores de macro e micronutrientes na parte aérea desta hortaliça. O experimento foi conduzido em casa de vegetação, em vasos de $5 \mathrm{dm}^{3}$ de volume com $4,8 \mathrm{~kg}$ de solo. O delineamento experimental foi em blocos casualizados, em fatorial 2 x 6, com três repetições. As fontes nitrogenadas, uréia e nitrato de cálcio, foram avaliadas em diferentes parcelamentos da dose de $105 \mathrm{mg} \mathrm{dm}^{-3}$ de $\mathrm{N}$ em três aplicações (na semeadura, 15 e 30 dias após a semeadura), nas seguintes proporções: $50 \%-50 \%-0 \%, 0 \%-50 \%-50 \%, 75 \%-25 \%-0 \%, 25 \%$ $75 \%-0 \%, 25 \%-50 \%-25 \%$ e $33 \%-33 \%-33 \%$. As plantas foram colhidas aos 40 dias após a semeadura. A melhor fonte de nitrogênio foi a nítrica (nitrato de cálcio), proporcionando maiores produções de massa fresca e seca da parte aérea, massa seca de raízes, produção de folhas por planta e maiores teores de N, Ca e Mn na parte aérea. Quanto ao parcelamento, os melhores resultados foram obtidos quando se realizou adubação na semeadura seguida de duas coberturas, uma aos 15 e outra aos 30 dias após a semeadura, nas proporções $33 \%-33 \%-33 \%$ e $25 \%-50 \%-25 \%$, para as duas fontes avaliadas.
\end{abstract}

Palavras-chave: Brassica chinensis L. var. parachinensis (Bailey) Sinskaja, uréia, nitrato de cálcio, acúmulo de nutrientes.

\section{ABSTRACT}

Split forms and sources of nitrogen fertilization for the flowering white cabbage production

The flowering white cabbage plant, Brassica chinensis L. var. parachinensis (Bailey) Sinskaja is often cultivated in China, Australia and other southeastern Asian countries and introduced in Brazil in 1992. There is little information regarding the mineral nutrition of this Brassica in the Brazilian conditions. The effect of sources and splitting of nitrogen in the productivity and ratio of macro and micronutrients in the shoot of this vegetable were evaluated. The experiment was carried out in a greenhouse in pots with capacity for $5 \mathrm{dm}^{3}$. The experimental design was a randomized block design, in a 2 x 6 factorial scheme with three replications. The nitrogen, calcium nitrate and urea sources were evaluated in different splitting for the $105 \mathrm{mg} \mathrm{dm}^{-3}$ of $\mathrm{N}$ dose, in the sowing, 15 and 30 days after sowing, in the following ratios: $50 \%-50 \%-0 \%, 0 \%-50 \%-50 \%, 75 \%-25 \%-$ $0 \%, 25 \%-75 \%-0 \%, 25 \%-50 \%-25 \%$ and $33 \%-33 \%-33 \%$. The plants were harvested 40 days after sowing. The biggest productions of fresh and dry weight of the shoot, dry matter of root, leaf number and the biggest ratio of $\mathrm{N}, \mathrm{Ca}$ and $\mathrm{Mn}$ in the shoot were reached with the nitric source (calcium nitrate). The best results concerning the splitting were obtained when fertilization took place during the sowing followed by two side dressing applications, one 15 days and another 30 days after sowing, in the proporcions 33\%-33\%-33\% and $25 \%-50 \%-25 \%$, for the sources evaluated.

Keywords: Brassica chinensis L. var. parachinensis (Bailey) Sinskaja, urea, calcium nitrate, nutrients accumulation.

\section{(Recebido para publicação em 23 de agosto de 2004 e aceito em 15 de agosto de 2005)}

\begin{abstract}
A couve-da-Malásia foi introduzida no Brasil, em 1992, por possuir altos teores de vitamina A, a partir de sementes trazidas da Malásia por Dr. Warwick E. Kerr, que adotou esta nomenclatura. Além disso, é de fácil cultivo e de ciclo curto (LEE, 1982; FERREIRA et al., 2002), podendo ser facilmente cultivada em hortas domésticas o ano inteiro, tornando-se uma fonte acessível de vitamina A.

Na literatura existem poucas informações referentes à nutrição mineral de brássicas. Segundo Hori (1965), estas variedades botânicas são grandes extratoras de nutrientes do solo e respondem com alta produtividade em espaço de tempo relativamente curto. Para Trani et al. (1994), elas apresentam grande capacidade de resposta ao nitrogê-
\end{abstract}

nio, verificando-se aumento na produtividade com aplicações da ordem de até $300 \mathrm{~kg} \mathrm{ha}^{-1}$. No entanto, é necessário, entre outros fatores, conhecer as exigências nutricionais de cada cultivar para se fornecer nutrientes em quantidades adequadas e equilibradas. Sabe-se que a couve-da-Malásia é altamente sensível à falta de nitrogênio, fósforo, potássio, enxofre (SOUSA, 1997) e boro (MOTA, 2001). Trabalhos realizados com a couve-da-Málasia na China e Austrália demonstraram a importância do nitrogênio para a sua produtividade. No Brasil, Zanão Jr. et al. (2005) verificaram que a melhor dose de $\mathrm{N}$ para a couve-da-Malásia foi de $210 \mathrm{~kg} \mathrm{ha}^{-1}$.

Segundo More e Morgan (1998), para o cultivo da couve-da-Malásia na Aus- trália, recomenda-se a aplicação, no plantio, de $50 \mathrm{~m}^{3} \mathrm{ha}^{-1}$ de esterco bovino; 1,25 a 2,0 $\mathrm{t} \mathrm{ha}^{-1}$ de superfosfato simples; 150 $300 \mathrm{~kg} \mathrm{ha}^{-1}$ de nitrato de amônio e cloreto de potássio. Na adubação de cobertura é recomendada a aplicação de $150-300 \mathrm{~kg}$ ha $^{-1}$ de nitrato de amônio e cloreto de potássio, uma a três semanas após a emergência. A variação da quantidade é verificada em função da textura do solo.

Para Malavolta (1974), quando se estudam aspectos relacionados à nutrição das hortaliças, deve-se atentar para o fato de que sendo o ciclo delas geralmente curto, essas culturas estão muito sujeitas a distúrbios nutricionais, pelo rápido crescimento, intensa produção, alta necessidade de nutrientes e intensa lixiviação de nutrientes no solo. 
No Brasil, pouco se conhece sobre as exigências nutricionais da couve-daMálasia. Até o momento, as recomendações de adubação para seu cultivo são feitas, com base naquilo que se conhece para hortaliças folhosas como a alface. Como é uma folhosa, a adubação nitrogenada e seu manejo são extremamente importantes para o sucesso da cultura, devendo-se ter informações específicas claras sobre a melhor fonte de nitrogênio e o parcelamento mais adequado desta adubação. O objetivo do presente trabalho foi avaliar o efeito de fontes e formas de parcelamento da adubação nitrogenada sobre a produtividade e teores foliares de macro e micronutrientes na parte aérea das plantas de couve-da-Malásia.

\section{MATERIAL E MÉTODOS}

O experimento foi realizado de maio a julho de 2004, conduzido em casa de vegetação, na Universidade Federal de Uberlândia (MG). As temperaturas média mínima e máxima na casa de vegetação, durante o período em que o experimento foi conduzido foram, respectivamente, $17^{\circ} \mathrm{C}$ e $26^{\circ} \mathrm{C}$.

A semeadura foi realizada em 09/06/ 2004, diretamente em vasos de $5 \mathrm{dm}^{3}$, com 4,8 $\mathrm{kg}$ de solo mantidos em espaçamento de 20 x $20 \mathrm{~cm}$. Foi utilizado solo da camada superficial (0 a $20 \mathrm{~cm}$ ) de um Latossolo Vermelho distrófico típico, textura média (273 $\mathrm{g} \mathrm{kg}^{-1}$ de argila). A análise do solo apresentou as seguintes características: $\mathrm{pH} \mathrm{H}_{2} \mathrm{O}(1: 2,5)=4,6 ; \mathrm{P}$ (Mehlich-1) = 0,2 $\mathrm{mg} \mathrm{dm}^{-3} ; \mathrm{K}^{+}$(Mehlich1) $=5,4 \mathrm{mg} \mathrm{dm}^{-3} ; \mathrm{Al}^{+3}, \mathrm{Ca}^{+2}, \mathrm{Mg}^{+2}, \mathrm{H}+\mathrm{Al}$, $=6,0 ; 1,0 ; 1,0$ e 40,0 $\mathrm{mmol}_{\mathrm{c}} \mathrm{dm}^{-3}$, respectivamente; saturação por bases $=4,22 \%$, matéria orgânica $=12 \mathrm{~g} \mathrm{~kg}^{-1} ; \mathrm{B}, \mathrm{Cu}, \mathrm{Fe}$, $\mathrm{Mn}, \mathrm{Zn}$ e $\mathrm{S}-\mathrm{SO}_{4}^{-2}=0,31 ; 0,9 ; 36 ; 0,3 ; 0,2$ e $6,0 \mathrm{mg} \mathrm{dm}^{-3}$, respectivamente.

$\mathrm{O}$ experimento foi conduzido em delineamento de blocos casualizados, distribuindo-se os tratamentos em esquema fatorial $2 \times 6$, com três repetições. O primeiro fator foram as fontes de nitrogênio, sendo nítrica e amídica e o segundo fator constituiu-se dos parcelamentos da aplicação da dose de $105 \mathrm{mg} \mathrm{dm}^{-3}$ de $\mathrm{N}$, o que corresponde a $210 \mathrm{~kg} \mathrm{ha}^{-1}$, em diferentes proporções, sendo: A) $50 \%$ na semeadura, $50 \%$ aos
15 dias após a semeadura (DAS) e $0 \%$ aos 30 DAS; B) $0 \%$ na semeadura, 50\% aos 15 DAS e $50 \%$ aos 30 DAS; C) $75 \%$ na semeadura, $25 \%$ aos 15 DAS e $0 \%$ aos 30 DAS; D) $25 \%$ na semeadura, $75 \%$ aos 15 DAS e $0 \%$ aos 30 DAS; E) $25 \%$ na semeadura, $50 \%$ aos 15 DAS e $25 \%$ aos 30 DAS e F) $33 \%$ na semeadura, $33 \%$ aos 15 DAS e $33 \%$ aos 30 DAS. Como fonte nitrogenada nítrica utilizou-se o nitrato de cálcio e como fonte amídica, a uréia. A uréia possui $44 \%$ de $\mathrm{N}$ na forma amídica $\left(\mathrm{NH}_{2}\right)$, que quando é aplicada ao solo, é rapidamente hidrolisada e se converte na forma amoniacal e o nitrato de cálcio possui $14 \%$ de $\mathrm{N}$ na forma nítrica e até $1,5 \%$ na forma amoniacal, além de possuir 18$19 \%$ de Ca e 0,5-1,5\% de magnésio.

O preparo do solo foi feito para cada vaso. A calagem foi realizada para elevar a saturação por bases a $70 \%$, conforme recomendação feita por Ribeiro et al. (1999) para a cultura da alface, aplicando-se uma dose correspondente a 2,0 $\mathrm{t} \mathrm{ha}^{-1}$ de calcário dolomítico calcinado (PRNT 100\%). O solo dos vasos foi incubado por 30 dias.

A semeadura foi realizada a $1 \mathrm{~cm}$ de profundidade, distribuindo-se cinco sementes por vaso. Após a emergência, foi realizado o desbaste, deixando-se uma planta por vaso, a mais vigorosa e centralizada. A rega foi feita duas vezes ao dia, utilizando-se $100 \mathrm{ml}$ de água por rega em cada vaso.

Na semeadura, foram aplicados 200 $\mathrm{mg} \mathrm{dm}{ }^{-3}$ de $\mathrm{P}_{2} \mathrm{O}_{5}, 30 \mathrm{mg} \mathrm{dm}^{-3}$ de $\mathrm{K}_{2} \mathrm{O}$ e $1 \mathrm{mg} \mathrm{dm}^{-3}$ de FTE BR-8, com $7 \% \mathrm{Zn}$, $2,5 \% \mathrm{~B}, 1 \% \mathrm{Cu}, 5 \% \mathrm{Fe}, 10 \% \mathrm{Mn}$ e $0,1 \%$ Mo. Foram realizadas duas coberturas com $25 \mathrm{mg} \mathrm{dm}^{-3}$ de $\mathrm{K}_{2} \mathrm{O}$, uma aos $15 \mathrm{e}$ outra aos 30 DAS. A fonte de $\mathrm{P}_{2} \mathrm{O}_{5}$ foi o superfosfato triplo e a de $\mathrm{K}_{2} \mathrm{O}$ o cloreto de potássio. As doses seguiram as recomendações feitas para a cultura da alface (RIBEIRO et al., 1999).

A colheita foi realizada 40 dias após a semeadura, para avaliação da massa fresca da parte aérea (MFPA), massa seca da parte aérea (MSPA), produção de folhas por planta (PF), massa seca de raízes (MSR), diâmetro do caule (DC), teores dos macronutrientes $(\mathrm{N}$, $\mathrm{P}, \mathrm{K}, \mathrm{Ca}, \mathrm{Mg}$ e S) e micronutrientes (B, $\mathrm{Cu}, \mathrm{Fe}, \mathrm{Mn}$ e $\mathrm{Zn}$ ) na parte aérea das plantas.
Na colheita, o sistema radicular foi separado da parte aérea. A produção de folhas foi obtida fazendo-se a contagem das mesmas no momento da avaliação da massa fresca da parte aérea. O diâmetro do caule foi medido com o auxílio de um paquímetro. As raízes foram lavadas cuidadosamente até a retirada do solo aderido às mesmas. $\mathrm{O}$ excesso de água foi retirado com o auxílio de papel toalha e em seguida o material (parte aérea e raízes) foi encaminhado para secar em estufa de circulação forçada de ar a $70^{\circ} \mathrm{C}$, até massa constante.

A análise química da parte aérea das plantas, para determinação dos teores de macro e micronutrientes, foi realizada segundo Bataglia et al. (1983).

Após a colheita, foi retirada uma amostra de solo dos vasos, para determinação do $\mathrm{pH}$ em água e teores de $\mathrm{Mn}$ e Zn disponíveis, segundo metodologia descrita por Silva et al. (1999).

Os dados obtidos foram inicialmente submetidos aos testes de normalidade (SHAPIRO-WILK) e homogeneidade (LEVENE), para se determinar, caso necessário, a transformação a ser adotada. Como as variâncias foram homogêneas entre os tratamentos e os resíduos da análise da variância apresentaram distribuição normal, nenhum deles foi transformado. O teste de Tukey a $5 \%$ de probabilidade foi utilizado para comparação entre as médias.

\section{RESULTADOS E DISCUSSÃO}

Considerando os fatores estudados, foi observada interação significativa e efeito significativo independente $(\mathrm{P} \leq 0,05)$ do parcelamento, apenas para a massa fresca da parte aérea. No que se refere às fontes, houve efeito significativo para a MSPA; MFPA; MSR; NF; teores foliares de N, Ca, Mn e Zn; pH em água e teores de Mn e Zn disponíveis no solo (Tabelas 1-4).

A produção de massa fresca da parte aérea foi superior quando a dose de $105 \mathrm{mg} \mathrm{dm}^{-3}$ de $\mathrm{N}$ foi parcelada nas três épocas, sendo semeadura, 15 DAS e 30 DAS, nas proporções de 25\%-50\%-25\% e $33 \%-33 \%-33 \%$.

A produção de massa fresca da parte aérea (produtividade agronômica) 
alcançada neste experimento foi inferior à máxima produção obtida por Zanão Júnior et al. (2005) $\left(114,55 \mathrm{~g}\right.$ planta $\left.^{-1}\right)$ com a utilização de $210 \mathrm{~kg} \mathrm{ha}^{-1}$ de $\mathrm{N}$, $30 \%$ na semeadura, $35 \%$ aos 15 e $35 \%$ aos 30 dias e por Ferreira et al. (2002), quando estudaram a mesma variedade em Uberlândia, em condições de campo, com adubação orgânica e mineral em diferentes espaçamentos (93 $\left.\mathrm{g} \mathrm{planta}^{-1}\right)$, utilizando $70 \mathrm{~kg} \mathrm{ha}^{-1}$ de N (42\% no plantio e $58 \%$ em cobertura, aos 15 DAS). A produção de massa fresca em alguns tratamentos foi semelhante à obtida por Dantas (1997), com aplicação de metanol e $80 \mathrm{~kg} \mathrm{ha}^{-1} \mathrm{de} \mathrm{N}$ em vasos mantidos em casa de vegetação (52 g plan$\left.\mathrm{ta}^{-1}\right)$ e superior à produção registrada por Hill (1990), em espaçamento 10 x 10 $\mathrm{cm}$, com aplicação de $200 \mathrm{~kg} \mathrm{ha}^{-1}$ de $\mathrm{N}$ (46 g planta $^{-1}$ ), em cultivo realizado em campo na Austrália.

A menor produção de massa fresca da parte aérea alcançada no presente trabalho, em relação à registrada por Zanão Júnior, et al. (2005), pode ser explicada pela época do ano em que os experimentos foram conduzidos. As plantas produzidas neste trabalho foram colhidas cinco dias antecipados, em relação ao trabalho daqueles autores, desenvolvido durante o verão, com temperatura mínima de $21^{\circ} \mathrm{C}$ e máxima de $29^{\circ} \mathrm{C}$, superiores às ocorridas durante a execução deste trabalho. Estes resultados indicam o maior desenvolvimento da parte aérea das plantas em temperaturas mais elevadas e o encurtamento do ciclo em temperaturas mais baixas. Dantas e Aragão (2000) verificaram que plantas desta variedade, semeadas em dezembro e agosto, foram fisiologicamente mais eficientes que aquelas produzidas nos outros meses e que plantas produzidas no mês de junho foram as que apresentaram menor crescimento.

Pelo que pôde ser observado, há necessidade de se realizar uma cobertura nitrogenada aos 15 e uma aos 30 dias após a semeadura. Estes resultados estão de acordo com os encontrados por Ferreira (2001), que verificou que aos 37 dias após a semeadura, a ausência da maioria dos nutrientes na solução nutritiva, utilizando a técnica do elemento faltante, reduziu significativamente a produtividade agronômica da couve-da-
Tabela 1. Produção de massa fresca da parte aérea (MFPA), massa seca da parte aérea (MSPA), massa seca de raízes (MSR), produção de folhas por planta (FP) e diâmetro de caule (DC), obtidos com as diferentes fontes e parcelamentos da adubação nitrogenada. Uberlândia, UFU, 2004.

\begin{tabular}{|c|c|c|c|c|c|c|c|c|}
\hline \multirow{2}{*}{ Fonte } & \multirow{2}{*}{\multicolumn{3}{|c|}{$\begin{array}{l}\text { Parcelamento de } \mathbf{N} \\
(\%)\end{array}$}} & MFPA & MSPA & MSR & \multirow{3}{*}{$\begin{array}{c}\begin{array}{c}\text { PF } \\
\left(\mathbf{n} .{ }^{\circ}\right)\end{array} \\
1200\end{array}$} & \multirow{2}{*}{$\begin{array}{c}\mathrm{DC} \\
(\mathrm{mm})\end{array}$} \\
\hline & & & & & planta $^{-1}$ & & & \\
\hline \multirow{6}{*}{ Nítrica } & 50 & 50 & 0 & $64,45 \mathrm{~b}$ & 4,69 & 0,53 & & 11,6 \\
\hline & 0 & 50 & 50 & $64,30 \mathrm{~b}$ & 4,91 & 0,32 & 11,67 & 11,7 \\
\hline & 75 & 25 & 0 & $61,21 \mathrm{c}$ & 4,19 & 0,54 & 12,00 & 12,2 \\
\hline & 25 & 75 & 0 & $70,96 \mathrm{~b}$ & 5,17 & 0,50 & 12,00 & 14,9 \\
\hline & 25 & 50 & 25 & $78,02 \mathrm{a}$ & 5,48 & 0,73 & 12,33 & 15,6 \\
\hline & 33 & 33 & 33 & $80,21 \mathrm{a}$ & 7,83 & 0,62 & 12,67 & 16,9 \\
\hline \multirow[t]{2}{*}{ Média } & & & & $69,85 \mathrm{~A}$ & $4,88 \mathrm{~A}$ & $0,54 \mathrm{~A}$ & $12,11 \mathrm{~A}$ & $13,8 \mathrm{~A}$ \\
\hline & 50 & 50 & 0 & $45,06 \mathrm{c}$ & 3,61 & 0,20 & 10,00 & 10,4 \\
\hline \multirow{5}{*}{ Amídica } & 0 & 50 & 50 & $49,95 \mathrm{c}$ & 3,72 & 0,35 & 10,33 & 12,3 \\
\hline & 75 & 25 & 0 & $56,21 \mathrm{~b}$ & 3,88 & 0,41 & 11,00 & 13,1 \\
\hline & 25 & 75 & 0 & $56,50 \mathrm{~b}$ & 4,58 & 0,42 & 11,33 & 13,4 \\
\hline & 25 & 50 & 25 & $65,50 \mathrm{a}$ & 4,60 & 0,53 & 11,33 & 15,7 \\
\hline & 33 & 33 & 33 & 68,03 a & 5,26 & 0,43 & 12,00 & 16,2 \\
\hline Média & & & & $56,83 \mathrm{~B}$ & $4,28 \mathrm{~B}$ & $0,39 \mathrm{~B}$ & $11,00 \mathrm{~B}$ & $13,5 \mathrm{~A}$ \\
\hline C.V.\% & & & & 14 & 15 & 17 & 10 & 9 \\
\hline
\end{tabular}

Letras minúsculas comparam médias do parcelamento dentro de cada fonte. Letras maiúsculas comparam médias entre as fontes. Médias seguidas da mesma letra não diferem entre si pelo teste de Tukey a 5\% de probabilidade.

Tabela 2. Teores de nitrogênio $(\mathrm{N})$, fósforo $(\mathrm{P})$, potássio $(\mathrm{K})$, cálcio $(\mathrm{Ca})$, magnésio $(\mathrm{Mg})$ e enxofre $(\mathrm{S})$ na parte aérea das plantas, obtidos com as diferentes fontes e parcelamentos da adubação nitrogenada. Uberlândia, UFU, 2004.

\begin{tabular}{lcccccc}
\hline \multirow{2}{*}{ Fonte } & \multicolumn{7}{c}{ Macronutriente ${\mathbf{~ ( ~} \mathbf{~ k g}^{-1}}^{-1}$} \\
\cline { 2 - 7 } & $\mathbf{N}$ & $\mathbf{P}$ & $\mathbf{K}$ & $\mathbf{C a}$ & $\mathbf{M g}$ & $\mathbf{S}$ \\
\hline Nítrica & $52,29 \mathrm{~A}$ & $6,25 \mathrm{~A}$ & $17,11 \mathrm{~A}$ & $30,82 \mathrm{~A}$ & $8,30 \mathrm{~A}$ & $6,38 \mathrm{~A}$ \\
Amídica & $40,95 \mathrm{~B}$ & $5,62 \mathrm{~A}$ & $17,97 \mathrm{~A}$ & $23,72 \mathrm{~B}$ & $7,43 \mathrm{~A}$ & $6,29 \mathrm{~A}$ \\
\hline C.V.\% & 14 & 22 & 17 & 13 & 16 & 10
\end{tabular}

Médias seguidas da mesma letra não diferem entre si pelo teste de Tukey a 5\% de probabilidade.

Tabela 3. Teores de boro (B), cobre $(\mathrm{Cu})$, ferro $(\mathrm{Fe})$, manganês $(\mathrm{Mn})$ e Zinco $(\mathrm{Zn})$ na parte aérea das plantas, obtidos com as diferentes fontes e parcelamentos da adubação nitrogenada. Uberlândia, UFU, 2004.

\begin{tabular}{lccccc}
\hline \multirow{2}{*}{ Fonte } & $\mathbf{5}$ Micronutriente $\left.\mathbf{( m g ~ k g}^{-1}\right)$ \\
\cline { 2 - 6 } & $\mathbf{B}$ & $\mathbf{C u}$ & $\mathbf{F e}$ & $\mathbf{M n}$ & $\mathbf{Z n}$ \\
\hline Nítrica & $128,26 \mathrm{~A}$ & $7,26 \mathrm{~A}$ & $161,89 \mathrm{~A}$ & $119,60 \mathrm{~A}$ & $79,47 \mathrm{~B}$ \\
Amídica & $126,17 \mathrm{~A}$ & $7,66 \mathrm{~A}$ & $175,91 \mathrm{~A}$ & $78,01 \mathrm{~B}$ & $90,40 \mathrm{~A}$ \\
\hline C.V.\% & 17 & 12 & 9 & 10 & 14 \\
\hline
\end{tabular}

Médias seguidas da mesma letra não diferem entre si pelo teste de Tukey a 5\% de probabilidade.

Tabela 4. Valores de pH em água e teores de Mn e Zn no solo, após a execução do experimento, obtidos com as diferentes fontes e parcelamentos da adubação nitrogenada. Uberlândia, UFU, 2004.

\begin{tabular}{lccc}
\hline Fonte & $\begin{array}{c}\mathrm{pH} \text { em água } \\
(\mathbf{1 : 2 , 5 )}\end{array}$ & $\begin{array}{c}\mathbf{M n} \\
\left(\mathbf{m g ~ d m}^{-3}\right)\end{array}$ & $\begin{array}{c}\mathbf{Z n} \\
\left(\mathbf{m g ~ d m}^{-3}\right)\end{array}$ \\
\hline Nítrica & $5,92 \mathrm{~A}$ & $1,20 \mathrm{~B}$ & $0,83 \mathrm{~B}$ \\
Amídica & $5,42 \mathrm{~B}$ & $1,86 \mathrm{~A}$ & $1,13 \mathrm{~A}$ \\
\hline C.V.\% & 4 & 13 & 9 \\
\hline
\end{tabular}

Médias seguidas da mesma letra não diferem entre si pelo teste de Tukey a 5\% de probabilidade. 
Malásia. Estas são as mesmas épocas de parcelamento recomendadas para a alface, segundo Ribeiro et al. (1999). Isso ocorreu porque o nutriente estava disponível no solo para a planta no período e na quantidade em que ela necessitava, em concentrações não tão altas para ocorrer lixiviação excessiva ou causar efeito negativo.

O maior valor de massa seca de raízes foi registrado para o parcelamento da dose de $\mathrm{N}$ com aplicação de $25 \%$ do $\mathrm{N}$ na semeadura e $50 \%$ aos 15 DAS e $25 \%$ aos 30 DAS para as duas fontes (Tabela 1). Esta produção foi inferior à obtida por Sousa (1997) e por Mota (2001), que foram de 2,84 $\mathrm{g} \mathrm{planta}^{-1} \mathrm{e}$ $0,93 \mathrm{~g} \mathrm{planta}^{-1}$, respectivamente.

A fonte de maior eficiência na produção de massa seca e fresca da parte aérea das plantas e de raízes foi a nítrica (nitrato de cálcio), que propiciou aumento de $23 \%$ em relação à fonte amídica (uréia), indicando, possivelmente, a preferência da couve-da-Malásia pela absorção do N na forma nítrica (Tabela 1). Segundo Larcher (2000), dentre outros fatores, a espécie/cultivar tem implicações nos ajustamentos metabólicos à absorção do amônio e do nitrato. A absorção do íon amônio causa grande demanda de esqueletos carbônicos, pois pode servir imediatamente para síntese de aminoácidos e compostos que contêm $\mathrm{N}$ reduzido. Grande consumo dos carboidratos pode ocorrer, se a fotossíntese for insuficiente, utilizando o carbono que estaria disponível para a planta converter em biomassa. Por outro lado, o nitrato quando absorvido é reduzido antes de sua assimilação, mas a demanda imediata por carboidratos é menor que a do amônio (EPSTEIN, 1975; FERREIRA et al., 1993; LARCHER, 2000).

A produção de folhas por planta foi muito semelhante, não influenciado significativamente pelo parcelamento, mas havendo efeito das fontes (Tabela 1). As plantas que receberam aplicação da fonte nítrica produziram $10 \%$ a mais de folhas do que as que as que receberam a fonte amídica.

O diâmetro do caule é uma característica avaliada para aceitação da couve-da-Malásia no mercado de hortaliças. Segundo Gallacher (1999), um produto de qualidade elevada tem diâmetro de caule entre $15 \mathrm{~mm}$ e $25 \mathrm{~mm}$. Os resultados obtidos no presente trabalho mostram que as plantas que ficaram incluídas dentro dessa amplitude foram as que receberam aplicação de $\mathrm{N}$ na semeadura e duas coberturas. Não houve diferença significativa em relação às fontes.

A maior absorção de Ca com aplicação da fonte nítrica é explicada pelo fato do nitrato de cálcio possuir 18-19\% de cálcio (Tabela 2). Além disso, plantas que recebem o $\mathrm{N}$ na forma nítrica aumentam a síntese de ácidos orgânicos, com conseqüente aumento na absorção de cátions, como $\mathrm{Ca}^{2+}, \mathrm{Mg}^{2+} \mathrm{e} \mathrm{K}^{+}$, para atingir o balanço interno de cargas (KIRKYB; KNIGHT, 1977).

Não existem dados na literatura sobre teores foliares adequados dos nutrientes para couve-da-Malásia. No entanto, os teores foliares de $\mathrm{N}$ e Ca obtidos neste trabalho são considerados adequados, segundo Ribeiro et al. (1999), para alface e para Brássicas (repolho e couve-flor).

Os maiores teores foliares de zinco obtidos com a fonte amídica podem estar relacionados à maior absorção e translocação deste nutriente, em relação aos demais, provavelmente devido à acidificação da rizosfera que adubação nitrogenada pode causar, provocada pela absorção do íon amônio, formado pela aplicação da uréia (FERREIRA et al., 1993). Este fato ficou comprovado com a análise do solo das parcelas que receberam adubação nitrogenada amídica, onde o pH em água se encontrava em torno de 5,4 em relação a 5,9, conseguido com a fonte nítrica (Tabela 4).

A acidificação da rizosfera, segundo Moraghan e Mascani Júnior (1991), aumenta a eficiência na absorção de micronutrientes metálicos $\mathrm{Zn}, \mathrm{Mn}, \mathrm{Cu}$ e $\mathrm{Fe}$, cuja disponibilidade é influenciada pelo $\mathrm{pH}$. Os teores de $\mathrm{Zn}$ e Mn no solo, significativamente maiores nas parcelas que receberam a aplicação da uréia, comprovam sua maior disponibilidade com o $\mathrm{pH}$ baixo (Tabela 4). Os teores foliares de Zn com a aplicação da fonte amídica foram significativamente maiores que a aplicação da fonte nítrica.

Os teores foliares de Mn foram maiores com a aplicação da fonte nítrica, apesar deste elemento estar disponível em maior quantidade no solo, com a fonte amídica. Isto pode ser explicado em parte, pela competição entre estes cátions $\mathrm{NH}_{4}^{+}$e $\mathrm{Mn}^{2+}$, pois a presença do amônio na solução diminuiu a absorção do Mn. Este fato também foi verificado por Fernandes et al. (2002) trabalhando com alface e diferentes fontes de nutrientes em cultivo hidropônico.

As maiores produções de massa fresca e massa seca da parte aérea, massa seca de raízes e os maiores teores foliares de $\mathrm{N}$ e Ca e Mn na parte aérea foram alcançadas com a fonte nítrica. Os maiores teores foliares de $\mathrm{Zn}$, menores teores disponíveis de $\mathrm{Mn}$ e $\mathrm{Zn}$ no solo e menores valores de $\mathrm{pH}$ do solo em água foram obtidos com a fonte amídica.

O nitrato de cálcio mostrou ser uma fonte nitrogenada mais viável em relação a uréia, apesar do custo relativo maior, pois proporcionou efeito alcalino no substrato e forneceu maiores quantidades de $\mathrm{N}$ às plantas, proporcionando maior produção de massa fresca e seca da parte aérea, massa seca de raízes e produção de folhas por planta.

Quanto ao parcelamento, melhores resultados para produção foram obtidos com as proporções 33\%-33\%-33\% e 25\%-50\%-25\%, para nitrato de cálcio e uréia, parcelados na semeadura, 15 e 30 dias após a semeadura.

\section{AGRADECIMENTOS}

Os autores agradecem à Prof. ${ }^{\mathrm{a}} \mathrm{Dr}^{\mathrm{a}}$ Marli A. Ranal pela revisão crítica e pelas valiosas sugestões, importantes na elaboração deste artigo.

\section{LITERATURA CITADA}

BATAGLIA, O.C.; FURLANI, A.M.C.; TEIXEIRA, J.P.F.; FURLANI, P.R.; GALLO, J.R. Métodos de análise química de plantas. Campinas: Instituto Agronômico, 1983. 48 p. (Boletim Técnico, 78). DANTAS, B.F.; ARAGÃO, C.A. Efeito de épocas de semeadura na produção de mudas de couve-da-Malásia (Brassica chinensis var. parachinensis). Cultura Agronômica, Ilha Solteira, v.9, n.1, p.91-100, 2000.

EPSTEIN, E. Nutrição mineral das plantas: princípios e perspectivas. São Paulo:USP, 1975. 344 p. FERNANDES, A.A.; MARTINEZ, H.E.P.; PEREIRA, P.R.G.; FONSECA, M.C.M. Produtividade, acúmulo de nitrato e estado nutricional de cultivares de alface, em hidroponia, em função de fontes de nutrientes. Horticultura Brasileira, Brasília, v.20, n.2, p.195-200, 2002.

FERREIRA, M.E.; CASTELLANE, P.D.; CRUZ, 
M.C.P. Nutrição e adubação de hortaliças. Piracicaba: POTAFOS, 1993. 487 p.

FERREIRA, R.N. Produtividade da couve-daMalásia (Brassica chinensis var. parachinensi (Bailey) Sinskaja) submetida a estresse nutricional ao longo o ciclo. 2001.33 p. (Monografia graduação), Universidade Federal de Uberlândia, Uberlândia.

FERREIRA, W.R.; RANAL, M.A.; FILGUEIRA,

F.A.R. Fertilizantes e espaçamento entre plantas na produtividade da couve-da-Malásia. Horticultura Brasileira, Brasília, v.20, n.4, p.635-640, 2002.

GALLACHER, D. Chinese flowering cabbage. Queensland, mai. 1999. Disponível em: <http:// www.ahs.cqu.edu.au/info/science/psg/AsianVeg/ ChinFlCabb.html>. Acesso em: 20 out. 2003.

HILL, T.R. The effect of nitrogenous fertilizer and plant spacing on the yield of three Chinese vegetables - Kai lan, Tsoi sum and Pak choi. Scientia Horticulturae, v.45, p.11-20, 1990.

HORI, Y. Técnica de cultivo e adubação de hortaliças. Tokyo: Nippon Ryuan, 1965. 64 p. Original japonês.

KIRKBY, E.A.; KNIGHT, A.H. Influence of the level of nitrate nutrition on ion uptake and assimilation, organic acid accumulation, and cation-anion balance in whole tomato plants. Plant Physiology, v.60, p.349-353, 1977.
LARCHER, W. Ecofisiologia vegetal. Tradução de: Carlos Henrique Britto de Assis Prado. 2. Ed. São Carlos: Rima Artes e Textos, 2000. 531 p.

LEE, S.H. Vegetable crops growing in China. Scientia Horticulturae, v.17, p.201-209, 1982.

MALAVOLTA, E. Nutrição mineral e adubação de plantas cultivadas. São Paulo: Pioneira, 1974. p.190-224.

MOORE, S.; MORGAN, W. Chinese flowering cabbage. The New Rural Industries. Ed.: K.W Hyde. Canberra, Rural Industries Research and Development Corporation: 178-181, 1998.

MORAGHAN, J.T.; MASCAGNI JR., H.J. Environmental and soil factors affecting micronutrient deficiencies and toxicities. In: MORTVEDT, J.J.; COX, F.R.; SHUMAN, L.M.; WELCH, R.M. (Ed.) Micronutrients in agriculture. 2.ed. Madison: SSSA, 1991. p.371-425.

MOTA, G.M.F. Cultivo de Brassica chinensis var. parachinensis (Bailey) Sinskaja na ausência de micronutrientes. 2001. 36 p. (Monografia graduação), Universidade Federal de Uberlândia, Uberlândia.
RIBEIRO, A.C.; GUIMARÃES, P.T.G.; ALVAREZ

V., V.H. Recomendações para o uso de corretivos e fertilizantes em Minas Gerais: $5^{\mathrm{a}}$ aproximação. Comissão de Fertilidade do Solo do Estado de Minas Gerais. Viçosa: UFV, 1999. 359 p.

SOUSA, E.R. Efeito da nutrição mineral na produtividade de couve-da-Malásia (Brassica chinensis var. parachinensis (Bailey) Sinskaja). 1997. 29 f. (Monografia graduação) - Universidade Federal de Uberlândia, Uberlândia

TRANI, P.E.; GRANJA, N.P.; BASSO, L.C.; DIAS, D.C.F.S., MINAMI, K. Produção e acúmulo de nitrato pela rúcula afetados por doses de nitrogênio, Horticultura Brasileira, Brasília, v.12, n.1, p. 25-29, 1994.

ZANÃO JÚNIOR, L.A.; LANA, R.M.Q.; RANAL, M.A. Doses de nitrogênio na produção de couve-da-Malásia. Horticultura Brasileira, Brasília, v.23, n.1, p.76-80, 2005. 